\title{
Transfermoral transcatheter aortic valve implantation using self-expanding Allegra bioprosthesis: One-year single-center outcomes
}

\author{
Joanna Milan ${ }^{1 *}$, Mirosław Gozdek ${ }^{2,3,4 *}$, Radosław Targoński ${ }^{8}$, \\ Mariusz Kowalewski ${ }^{4,5,6}$, Aleksandra Stańska ${ }^{8}$, Marcin Fijałkowski ${ }^{1}$, \\ Romuald Lango ${ }^{7}$, Miłosz Jaguszewski ${ }^{1}$, Dariusz Jagielak ${ }^{8}$
}

${ }^{1} 1^{\text {st }}$ Department of Cardiology, Medical University of Gdansk, Poland; ${ }^{2}$ Department of Cardiology and Internal Medicine, Nicolaus Copernicus University, Collegium Medicum in Bydgoszcz, Poland;

${ }^{3}$ Department of Cardiac Surgery, Medinet Heart Center Ltd., Wroclaw, Poland; ${ }^{4}$ Thoracic Research Center, Collegium Medicum, Nicolaus Copernicus University, Innovative Medical Forum, Bydgoszcz, Poland;

${ }^{5}$ Clinical Department of Cardiac Surgery, Central Clinical Hospital of the Ministry of Interior and Administration, Center of Postgraduate Medical Education, Warsaw, Poland; ${ }^{6}$ Department of Cardio-Thoracic Surgery, Heart and Vascular Center, Maastricht University Medical Center, Maastricht, The Netherlands; ${ }^{7}$ Department of Cardiac Anesthesiology, Medical University of Gdansk, Poland

${ }^{8}$ Department of Cardiac and Vascular Surgery, Medical University of Gdansk, Poland

\begin{abstract}
Background: The NAUTILUS study aimed to evaluate the safety and performance of the Allegra bioprosthesis in high-risk recipients undergoing transcatheter aortic valve implantation and previously reported 30-day outcomes. In the current investigation 1-year results of the trial are presented.

Methods: Twenty-seven recipients with severe, symptomatic aortic valve stenosis at high surgical risk, who underwent treatment using the next-generation self-expanding Allegra via transfemoral approach were prospectively enrolled. Clinical endpoints assessed were: mortality, stroke, permanent pacemaker implantation, New York Heart Association class and re-hospitalizations. Prosthetic valve performance evaluation comprised of: mean gradient, effective orifice area and paravalvular leak.

Results: Patients were elderly ( $82.8 \pm 4.2$ years) and predominantly female $(n=19,70.4 \%)$. All of them were deemed to be at high surgical risk with a mean logistic EuroSCORE of $12.5 \pm 6.7$. The bioprosthesis was successfully implanted in $92.6 \%$ of the cases $(n=25)$. At 1-year, all-cause mortality was $12.0 \%(n=3)$ and stroke was $4.0 \%(n=1)$. Three (12\%) of patients developed complete atrioventricular block and received permanent pacemakers. $84 \%$ of patients were in New York Heart Association class II or lower. Need for subsequent hospitalization arose in $48 \%$ patients. The echocardiographic assessment confirmed an acceptable hemodynamic profile of the Allegra with low mean transprosthetic gradient $(9.5 \pm 3.4 \mathrm{mmHg})$, absence of severe paravalvular leak and a 20\%-presence of moderate paravalvular leak.

Conclusions: The current follow-up observation study shows that the Allegra was associated with a satisfactory safety profile and hemodynamic performance at 1-year after implantation. (Cardiol J 2021; 28, 6: 825-830)
\end{abstract}

Key words: Allegra, NAUTILUS clinical study, transcatheter aortic valve implantation

Address for correspondence: Dr. Mirosław Gozdek, Department of Cardiology and Internal Medicine, Nicolaus Copernicus University, Collegium Medicum in Bydgoszcz, ul. M. Skłodowskiej-Curie 9, 85-094 Bydgoszcz, Poland, e-mail: gozdekm@wp.pl

Received: 29.04.2020

Accepted: 25.01.2021

Early publication date: 17.08 .2021

*Both authors equally contributed to the study.

This article is available in open access under Creative Common Attribution-Non-Commercial-No Derivatives 4.0 International (CC BY-NC-ND 4.0) license, allowing to download articles and share them with others as long as they credit the authors and the publisher, but without permission to change them in any way or use them commercially. 


\section{Introduction}

Since its introduction by Cribier in 2007 [1], transcatheter aortic valve implantation (TAVI) has complemented surgical aortic valve replacement (SAVR) in patients with severe symptomatic aortic valve stenosis (AVS). This minimally invasive technique at first presented an opportunity to treat inoperable individuals and ultimately has become common and standard in higher-risk patients. The Allegra TAVI System (NVT, Germany) bioprosthesis is a next-generation, self-expanding device, dedicated for TAVI and is designed to overcome the limitations of first-generation systems including firstly, paravalvular leak (PVL) and the necessity for permanent pacemaker implantation (PPI). The first-in-human clinical trial with implantations of the Allegra took place in 2013 by Wenaweser et al. [2]. To date, several conducted studies showed encouraging short-term outcomes in treating patients with severe aortic native valve stenosis using New Valve Technology (NVT) devices [2-4], but longerterm results are lacking. Herein, are presented 1 -year single-center results with the Allegra.

\section{Methods}

NAUTILUS (NVT trAnsfemoral mUlticentric aorTIc valve pivotaL stUdy for Safety and effectiveness - DRKS00006042) is a single-arm clinical study conducted at 8 centers in 3 countries (Switzerland, Poland, and Brazil), designed to assess the safety and performance of the Allegra and, as it has been described in detail before, along with implantation protocol [3].

In brief, we previously reported on a single-center's early outcomes with the Allegra (Suppl. Fig. 1) implanted in 26 patients accepted by the Heart Team to undergo transfemoral TAVI. All patients suffered from severe, symptomatic AVS and met the NAUTILUS eligibility criteria. The main inclusion criteria were: 1 ) age $\geq 75$ years; 2) symptomatic (New York Heart Association [NYHA] class II or greater), severe degenerative native aortic stenosis (mean transvalvular pressure gradient $>40 \mathrm{mmHg}$ and/or aortic jet velocity $>4.0 \mathrm{~m} / \mathrm{s}$ and/or aortic valve area of $<1.0 \mathrm{~cm}^{2}$ [or aortic valve area index $\left.\leq 0.6 \mathrm{~cm}^{2} / \mathrm{m}^{2}\right]$ ); 3) high risk for surgical aortic valve replacement with a logistic EuroSCORE $\geq 20 \%$ or documented agreement of the Heart Team that the patient is at high risk for surgery due to frailty and/or coexisting comorbidities. Amongst others, the protocol defined exclusion criteria comprised: 1) unicuspid or bicuspid valve disease; 2 ) non-calcified aortic valve disease; 3 ) mixed valve disease with predominant aortic regurgitation greater than $3+$ or with associated severe (greater than $3+$ ) mitral regurgitation; 4) aortic annulus size $<19 \mathrm{~mm}$ or $>29 \mathrm{~mm}$; 5 ) type of femoral access, or any other anatomical conditions that prevented the safe placement of an 18 French introducer sheath and manipulation of the TAVI system (e.g. severe femoral-iliac obstructive calcification or tortuosity).

Patients were followed-up for 1 year. Written informed consent was obtained from each participant. The study was approved by the local ethics committee.

The data for the clinical trial was collected prospectively in an outpatient setting by using a dedicated electronic case report form. End points in the analysis included all-cause mortality, stroke, PPI, re-hospitalizations, re-hospitalizations for cardiovascular causes. Most patients underwent transthoracic echocardiography. Hemodynamic prosthesis performance assessment included mean pressure gradient, effective orifice area, presence and grade of PVL. Continuous variables are presented as mean \pm standard deviation. Categorical variables are given as frequencies and percentages and were compared by the Fisher exact test. A two-sided p-value $<0.05$ was considered statistically significant if applicable. Statistical analysis was performed using STATISTICA 12.0 PL (StatSoft).

\section{Results}

Baseline characteristics of the study group is listed in Table 1. The patients' population was elderly with a mean age of $82.8 \pm 4.2$ years, $70.4 \%$ were female and the mean logistic EuroSCORE was $12.5 \pm 6.7$. Twenty-six patients were implanted with the Allegra valve. The procedure was successfully completed in $25(92.6 \%)$ of them. One individual required open-heart aortic valve replacement due to dislocation of the prosthesis into the left ventricle. The patient selection process and reasons for exclusion of proportions of them are described in Supplementary Figure 2. Mean follow-up was $12.4 \pm 2.3$ months. Three (12\%) patients died within the study period. Stroke was recorded in 1 (4\%) individual. Three (12\%) recipients developed complete atrioventricular block and received permanent pacemakers. Lasting improvement in patients' functional class was noted (Fig. 1). Most individuals (84\%) were in II or less NYHA class. Twelve patients (48\%) needed rehospitalization during follow-up period. 
Table 1. Baseline characteristics and parameters $(\mathrm{n}=27)$.

\begin{tabular}{lc}
\hline Age [years] & $82.8 \pm 4.2$ \\
Male & $8(29.6 \%)$ \\
Female & $19(70.4 \%)$ \\
Logistic EuroSCORE [\%] & $12.5 \pm 6.7$ \\
Hypertension & $22(81.5 \%)$ \\
Diabetes & $14(51.8 \%)$ \\
COPD & $5(18.5 \%)$ \\
Coronary artery stenosis $>50 \%$ & $2(7.4 \%)$ \\
Previous myocardial infarction & $7(25.9 \%)$ \\
Previous coronary surgery & $4(14.8 \%)$ \\
Previous coronary angioplasty & $12(44.4 \%)$ \\
Previous stroke or TIA & $1(3.7 \%)$ \\
Creatinine clearance (<60 mL/min) & $7(25.9 \%)$ \\
NYHA: & \\
I & $0(0 \%)$ \\
II & $3(11.1 \%)$ \\
III & $23(85.2 \%)$ \\
IV & $1(3.7 \%)$ \\
Conduction disorders (LBBB, RBBB, AVB) & $2(7.4 \%)$ \\
Pre-existing permanent pacemaker & $3(11.1 \%)$ \\
Aortic valve insufficiency ( $\geq$ mild) & $11(40.7 \%)$ \\
Mitral valve insufficiency $(\geq$ mild) & $18(66.7 \%)$ \\
\hline
\end{tabular}

AVB - atrioventricular block; COPD - chronic obstructive pulmonary disease; LBBB — left bundle branch block; NYHA - New York Heart Association functional class; RBBB — right bundle branch block; TIA — transient ischemic attack

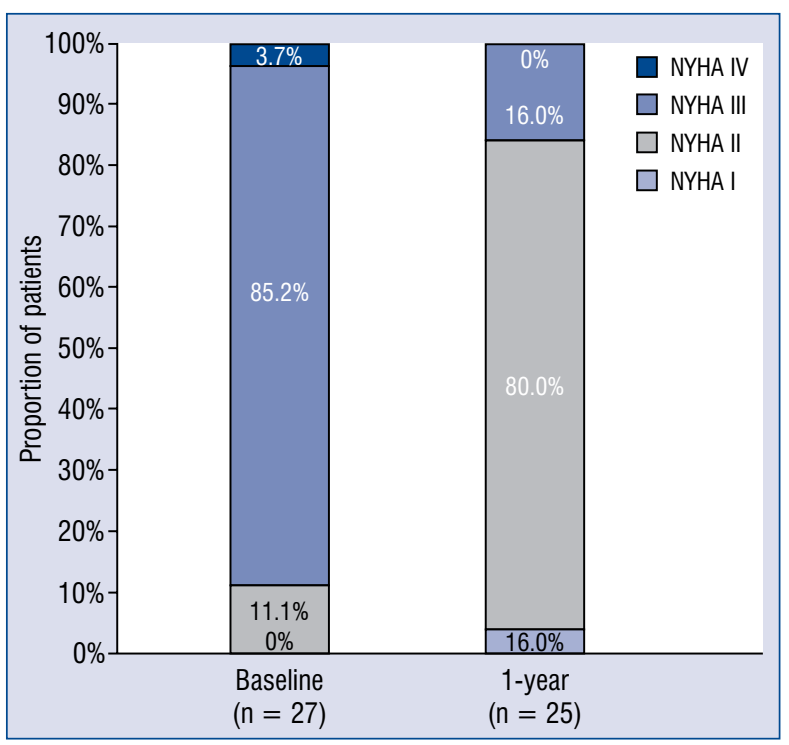

Figure 1. New York Heart Association (NYHA) functional class at baseline and after 1 year of follow-up.
Table 2. Clinical outcomes and adverse events at 1 -year follow-up $(n=25)$.

\begin{tabular}{|c|c|}
\hline All-cause mortality & $3(12 \%)$ \\
\hline Cardiovascular mortality & $3(12 \%)$ \\
\hline Myocardial infarction & $0(0 \%)$ \\
\hline Stroke and/or TIA & $1(4 \%)$ \\
\hline Minor bleeding & $1(4 \%)$ \\
\hline Renal failure & $1(4 \%)$ \\
\hline Vascular complication & $0(0 \%)$ \\
\hline Sepsis & $2(8 \%)$ \\
\hline Endocarditis & $0(0 \%)$ \\
\hline Permanent pacemaker implantation & $3(12 \%)$ \\
\hline $\begin{array}{l}\text { Valve-related dysfunction requiring } \\
\text { repeat procedure }\end{array}$ & $0(0 \%)$ \\
\hline \multicolumn{2}{|l|}{ NYHA: } \\
\hline I & $1(4 \%)$ \\
\hline II & $20(80 \%)$ \\
\hline III & $4(16 \%)$ \\
\hline IV & $0(0 \%)$ \\
\hline Readmission & $12(48 \%)$ \\
\hline \multicolumn{2}{|l|}{ Cause of readmission } \\
\hline \multicolumn{2}{|l|}{ Cardiovascular: } \\
\hline CHF exacerbation & $2(8 \%)$ \\
\hline Hypertension & $2(8 \%)$ \\
\hline Complete AVB & $1(4 \%)$ \\
\hline Supraventricular arrhythmia & $1(4 \%)$ \\
\hline Stroke & $1(4 \%)$ \\
\hline \multicolumn{2}{|l|}{ Other: } \\
\hline Sepsis & $1(4 \%)$ \\
\hline Delirium & $1(4 \%)$ \\
\hline Dehydration & $1(4 \%)$ \\
\hline Bronchitis & $1(4 \%)$ \\
\hline Infection of the wound & $1(4 \%)$ \\
\hline
\end{tabular}

AVB - atrioventricular block; CHF - chronic heart failure; NYHA New York Heart Association; TIA — transient ischemic attack

Seven individuals (58\%) had cardiovascular reason for subsequent hospital stay, but none was prosthesis-related. The cardiovscular causes were: chronic heart failure exacerbation in two patients, hypertension in another two, complete atrio-ventricular block, supraventricular arrhythmia and stroke (Table 2).

The echocardiographic assessment on followup showed excellent hemodynamic performance. The study group had a low mean transprosthetic gradient $(9.5 \pm 3.4 \mathrm{mmHg})$ and suitable effective aortic orifice area $\left(1.48 \pm 0.39 \mathrm{~cm}^{2}\right)$. The major- 


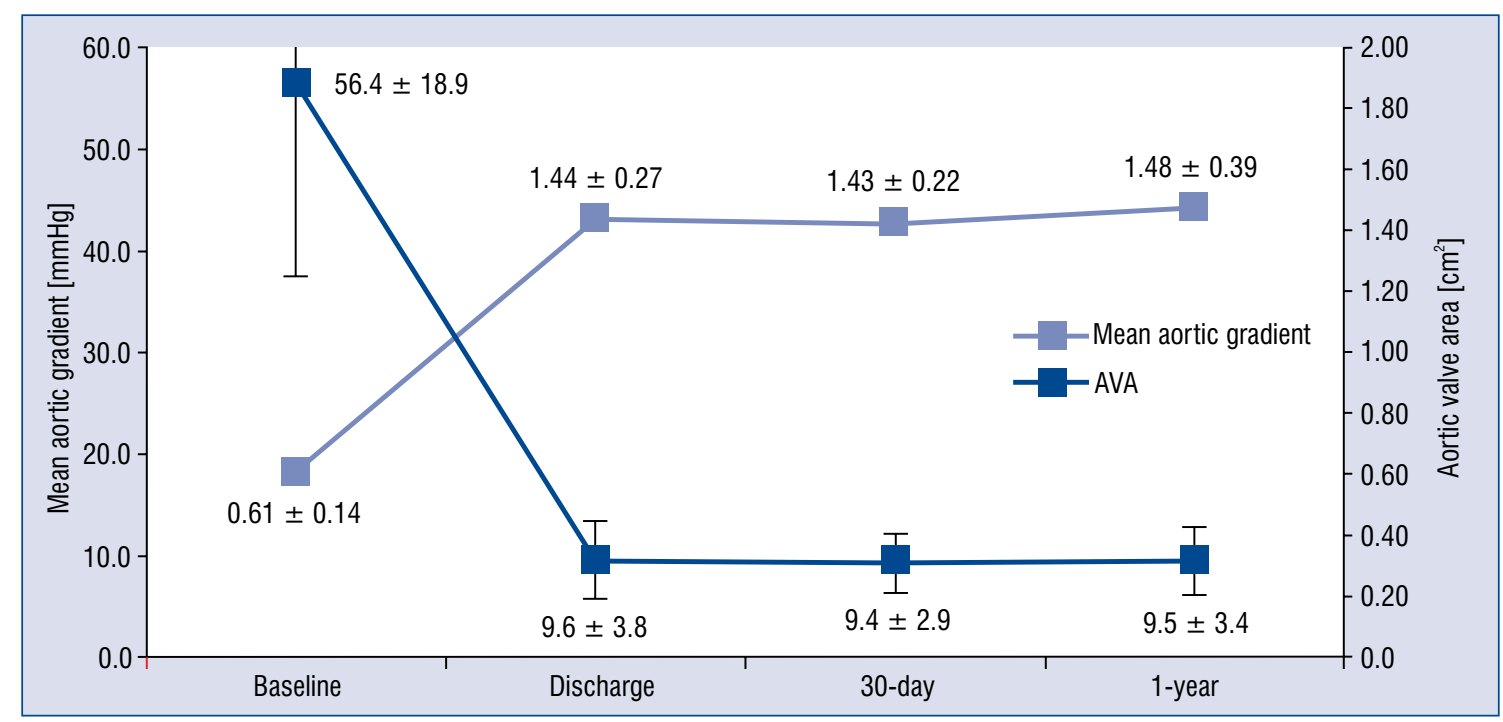

Figure 2. Analysis of mean transprosthetic gradient and aortic valve area (AVA) before and after transcatheter aortic valve implantation.

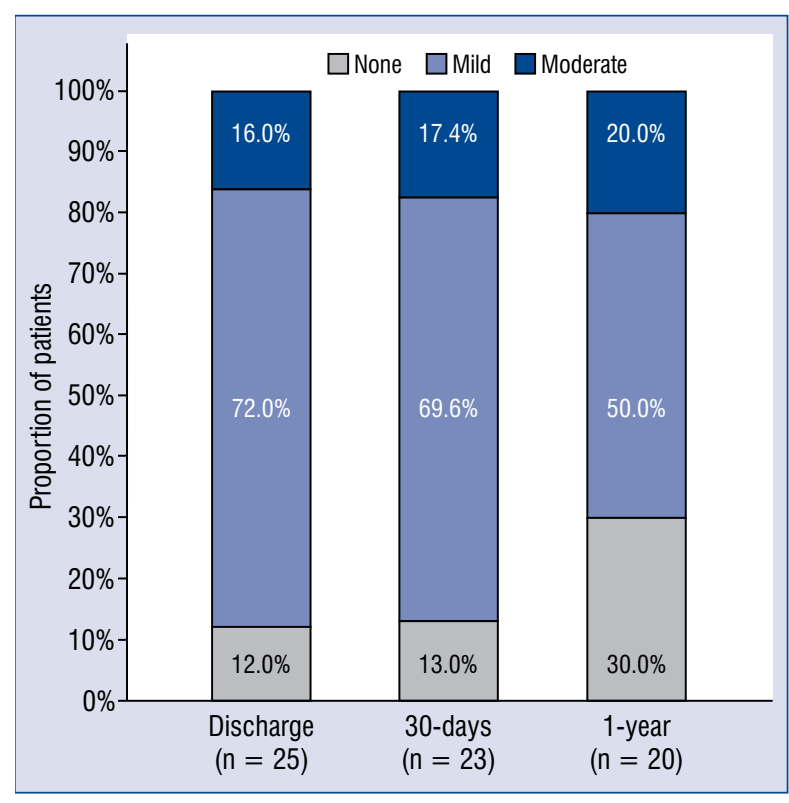

Figure 3. Analysis of paravalvular leak in observations.

ity of patients $(80.0 \%)$ had only mild or less PVL, while $20 \%$ moderate and $0 \%$ severe were noted. Figures 2 and 3 present changes of prosthetic aortic valve area, mean transprosthetic gradient and paraprosthetic leak in the study population during observation.

\section{Discussion}

The current study is the single-center experience of the next-generation, self-expanding, tran- scatheter and transfemoral Allegra bioprosthesis and, according to available research, is the only one that presents outcomes in long-term follow-up. The study revealed a favorable valve hemodynamic profile with low transvalvular gradient and no severe PVLs. Three deaths, one cerebrovascular incident, as well as a low rate of permanent pacemaker implantation (12\%) were recorded during the followup period. Twelve patients needed subsequent hospitalization.

The study revealed no severe PVL. However, $20 \%$ moderate and $50 \%$ mild PVLs occurred in the Allegra recipients at 1-year. Only two transcatheter devices were commercially available within the initial few years after the first procedure: the self-expandable CoreValve (Medtronic, USA) and the balloon-expandable Sapien (Edwards Lifesciences Corporation, USA). Early-generation transcatheter valves, despite providing good clinical outcomes, were not free from shortcomings such as a high rate of conduction abnormalities demanding PPI, vascular complications or more importantly a higher incidence of PVL, which was consequently associated with increased late mortality and higher rate of other adverse clinical incidents as compared to SAVR [5, 6]. Several potential causes of PVL such as severe native valve calcification, suboptimal artificial valve sizing, positioning and deployment, and prosthesis construction itself are universally reported across available literature. To minimize these shortcomings technological innovations, with respect to both delivery systems and the valve itself were developed in next-generations 
devices, including the Allegra. The outer part of the valve's stent is covered by $12-\mathrm{mm}$ bovine pericardial sealing skirt reducing the risk of significant paravalvular leak. The NVT system is able to reposition and retrieve the prosthesis in case of malposition or a suboptimal result. The Allegra valve has features allowing for very precise positioning. The presence of radiopaque markers in the delivery system as well as at the transition between the annular skirt and the bottom of the leaflets markedly facilitates the procedure, by enabling direct and clear visualization of the optimal implantation height and the limits of the sealing skirt.

A different grade of PVL was a common complication of early-generation TAVI devices and was associated with worse survival [7, 8]. Moreover, long-term follow-up data suggested that even mild paravalvular regurgitation was associated with increased late mortality with the balloon-expandable Sapien [5] and with the self-expandable CoreValve, early-generation valves $[9,10]$. Moderate to severe PVL occurred in $7.8 \%$ of CoreVale implantations and mild paravalvular aortic regurgitation was reached in one-third of cases in 1-year observation by Adams et al. [11] as well as $4.2 \%$ and $29.1 \%$, respectively, in a study by Popma et al. [12]. The next iteration of the Medtronic valve, the Evolut $\mathrm{R}$, was associated with $1.2 \%$ of moderate PVL at 1-year observation by Manoharan et al. [13]. Newer-generation, self-expanded the Acurate neo (Boston Scientific) in study by Mauri et al. [14] presented no severe, $3.9 \%$ moderate and $47.1 \%$ mild PVL at 1-year follow-up.

Popma et al. [12] revealed that the frequency of moderate or severe PVL was lower 12 months after CoreValve TAVI $(4.2 \%)$ than at discharge $(10.7 \%)$. Oh reported $83 \%$ of CoreValve recipients have at least one degree of regression in PVL during 1-year follow-up [15]. Structural properties of nitinol-based frame are probably the explanation of this phenomenon. Progressive expansion of the self-expanding valve improved paravalvular sealing. Results of the current study confirm the trend of decreasing PVL frequency over time, but only concerning mild PVL.

The overall risk of the early permanent atrioventricular conduction disturbances and need for PPI following TAVI procedures varies, but remains around $17 \%$ [16]. In comparison to the balloon-expandable valves, the self-expandable TAVI prostheses have a slightly higher rate of postprocedural atrio-ventricular conduction block requiring pacemaker implantation $(28 \%)[17,18]$. In our study only $12 \%$ of patients required PPI in longer follow-up compared to $8 \%$ in 30-day observation. In comparison to other self-expandable older and newer-generation prostheses. This is a very promising result. Adams et al. [11] and Popma et al. [12] reported $22.3 \%$ and $26.2 \%$ need of PPI for CoreValve, Manoharan [13] 19.7\% for Evolut R recipients in 1-year. Such a good result may be related to a high valve implantation facilitated by refined deployment technology and the Allegra design. However, it seems atrio-ventricular conduction disturbances revealed a month after the procedure are rather not related to TAVI.

The effect of PPI on long-term outcomes after TAVI remains inconclusive [19, 20]. Post-TAVI PPI was reported as an independent predictor of 1-year mortality [19] and was also associated with a longer duration of hospitalization and higher rates of re-hospitalization at 1 year [21]. In contrast, an analysis including more than 1500 TAVI procedures the need for PPI did not increase overall mortality, cardiovascular death or re-hospitalization for heart failure within 2 years [22]. Moreover, Engborg et al. [23] reported even higher survival rate in TAVI-patients with a permanent pacemaker implanted.

The present study revealed $12 \%$ of mortality. In the article by Adams et al. [11] as well as by Popma et al. [12] concerning 1-year results after TAVI utilizing the early-generation self-expandable CoreValve, mortality was estimated at $13.9 \%$ and $24.3 \%$, respectively. With regards to the nextgeneration devices, Manoharan et al. [13] reported 8.9\% of mortality among Evolut R self-expandable prosthetic valve recipients at high or greater surgical risk. In turn, Barth et al. [24] and Mauri et al. [14] in studies with the self-expandable Acurate neo implanted in the high surgical risk patients revealed $16.9 \%$ and $8.3 \%$ mortality ratios in 1 -year observations, respectively.

In the current investigation, despite a disturbingly high rate of moderate and mild PVL, mortality remains low, lower than recorded in early generation self-expandable valves and is comparable with the other next-generation devices.

These results suggest that the Allegra has an acceptable efficacy profile in treating elderly patients with severe symptomatic AVS, although further studies are warranted to fully elucidate this issue.

The present study has some important limitations. It is an observational, single-arm study of a small sample size which, per se, precludes any in-depth comparison against a control group or detailed analyses related to uncommonly occurring events. 


\section{Conclusions}

This prospective study shows a good safety and performance profile of the Allegra. The valve has a satisfactory hemodynamic performance and encouraging clinical results with a low rate of pacemaker implantations.

\section{Conflict of interest: None declared}

\section{References}

1. Cribier A, Eltchaninoff H, Bash A, et al. Percutaneous transcatheter implantation of an aortic valve prosthesis for calcific aortic stenosis: first human case description. Circulation. 2002; 106(24): 3006-3008, doi: 10.1161/01.cir.0000047200.36165.b8, indexed in Pubmed: 12473543.

2. Wenaweser P, Stortecky S, Schütz T, et al. Transcatheter aortic valve implantation with the NVT Allegra transcatheter heart valve system: first-in-human experience with a novel self-expanding transcatheter heart valve. EuroIntervention. 2016; 12(1): 71-77, doi: 10.4244/EIJV12I1A13, indexed in Pubmed: 27173865.

3. Jagielak D, Stanska A, Klapkowski A, et al. Transfermoral aortic valve implantation using self-expanding New Valve Technology (NVT) Allegra bioprosthesis: A pilot prospective study. Cardiol J. 2021; 28(3): 384-390, doi: 10.5603/CJ.a2019.0019, indexed in Pubmed: 30761515.

4. Cuevas O, Moreno R, Pascual-Tejerina V, et al. The Allegra transcatheter heart valve: European multicentre experience with a novel self-expanding transcatheter aortic valve. EuroIntervention. 2019; 15(1): 71-73, doi: 10.4244/EIJ-D-18-00861, indexed in Pubmed: 30777839.

5. Kodali S, Williams M, Smith C, et al. Two-Year Outcomes after Transcatheter or Surgical Aortic-Valve Replacement. N Engl J Med. 2012; 366(18): 1686-1695, doi: 10.1056/nejmoa1200384.

6. Jones BM, Tuzcu EM, Krishnaswamy A, et al. Prognostic significance of mild aortic regurgitation in predicting mortality after transcatheter aortic valve replacement. J Thorac Cardiovasc Surg. 2016; 152(3): 783-790, doi: 10.1016/j.jtcvs.2016.05.023, indexed in Pubmed: 27321435.

7. Tamburino C, Capodanno D, Ramondo A, et al. Incidence and predictors of early and late mortality after transcatheter aortic valve implantation in 663 patients with severe aortic stenosis. Circulation. 2011; 123(3): 299-308, doi: 10.1161/CIRCULATIONAHA.110.946533, indexed in Pubmed: 21220731.

8. Athappan G, Patvardhan E, Tuzcu EM, et al. Incidence, predictors, and outcomes of aortic regurgitation after transcatheter aortic valve replacement: meta-analysis and systematic review of literature. J Am Coll Cardiol. 2013; 61(15): 1585-1595, doi: 10.1016/j.jacc.2013.01.047, indexed in Pubmed: 23500308.

9. Jones BM, Tuzcu EM, Krishnaswamy A, et al. Prognostic significance of mild aortic regurgitation in predicting mortality after transcatheter aortic valve replacement. J Thorac Cardiovasc Surg. 2016; 152(3): 783-790, doi: 10.1016/j.jtcvs.2016.05.023, indexed in Pubmed: 27321435.

10. Little SH, Oh JK, Gillam L, et al. Self-Expanding transcatheter aortic valve replacement versus surgical valve replacement in patients at high risk for surgery: a study of echocardiographic change and risk prediction. Circ Cardiovasc Interv. 2016; 9(6), doi: 10.1161/CIRCINTERVENTIONS.115.003426, indexed in Pubmed: 27313280.

11. Adams DH, Popma JJ, Reardon MJ, et al. U.S. CoreValve Clinical Investigators. Transcatheter aortic-valve replacement with a self-expanding prosthesis. N Engl J Med. 2014; 370(19):
1790-1798, doi: 10.1056/NEJMoa1400590, indexed in Pubmed: 24678937.

12. Popma J, Adams D, Reardon M, et al. Transcatheter aortic valve replacement using a self-expanding bioprosthesis in patients with severe aortic stenosis at extreme risk for surgery. J Am Coll Cardiol. 2014; 63(19): 1972-1981, doi: 10.1016/j.jacc.2014.02.556.

13. Manoharan G, Van Mieghem NM, Windecker S, et al. 1-Year outcomes with the evolut $r$ self-expanding transcatheter aortic valve: from the international FORWARD study. JACC Cardiovasc Interv. 2018; 11(22): 2326-2334, doi: 10.1016/j.jcin.2018.07.032, indexed in Pubmed: 30466832.

14. Mauri V, Kim WK, Abumayyaleh M, et al. Short-Term outcome and hemodynamic performance of next-generation self-expanding versus balloon-expandable transcatheter aortic valves in patients with small aortic annulus: a multicenter propensity-matched comparison. Circ Cardiovasc Interv. 2017; 10(10), doi: 10.1161/CIRCINTERVENTIONS.117.005013, indexed in Pubmed: 28951395.

15. Oh JK, Little SH, Abdelmoneim SS, et al. CoreValve U.S. Pivotal Trial Clinical Investigators. Regression of Paravalvular Aortic Regurgitation and Remodeling of Self-Expanding Transcatheter Aortic Valve: An Observation From the CoreValve U.S. Pivotal Trial. JACC Cardiovasc Imaging. 2015; 8(12): 1364-1375, doi: 10.1016/j.jcmg.2015.07.012, indexed in Pubmed: 26508386.

16. Siontis GCM, Jüni P, Pilgrim T, et al. Predictors of permanent pacemaker implantation in patients with severe aortic stenosis undergoing TAVR: a meta-analysis. J Am Coll Cardiol. 2014; 64(2): 129-140, doi: 10.1016/j.jacc.2014.04.033, indexed in Pubmed: 25011716.

17. Hayashida K, Morice MC, Chevalier B, et al. Sex-related differences in clinical presentation and outcome of transcatheter aortic valve implantation for severe aortic stenosis. J Am Coll Cardiol. 2012; 59(6): 566-571, doi: 10.1016/j.jacc.2011.10.877, indexed in Pubmed: 22300690.

18. Khawaja MZ, Rajani R, Cook A, et al. Permanent pacemaker insertion after CoreValve transcatheter aortic valve implantation: incidence and contributing factors (the UK CoreValve Collaborative). Circulation. 2011; 123(9): 951-960, doi: 10.1161/CIRCULATIONAHA.109.927152, indexed in Pubmed: 21339482.

19. Buellesfeld L, Stortecky S, Heg D, et al. Impact of permanent pacemaker implantation on clinical outcome among patients undergoing transcatheter aortic valve implantation. J Am Coll Cardiol. 2012; 60(6): 493-501, doi: 10.1016/j.jacc.2012.03.054, indexed in Pubmed: 22726632.

20. Dizon JM, Nazif TM, Hess PL, et al. PARTNER Publications Office. Chronic pacing and adverse outcomes after transcatheter aortic valve implantation. Heart. 2015; 101(20): 1665-1671, doi: 10.1136/heartjnl-2015-307666, indexed in Pubmed: 26261157.

21. Nazif TM, Dizon JM, Hahn RT, et al. Predictors and clinical outcomes of permanent pacemaker implantation after transcatheter aortic valve replacement: the PARTNER (placement of aortic transcatheter valves) trial and registry. J Am Coll Cardiol Intv. 2015; 8: 60-69, doi: 10.1016/j.jcin.2014.07.022, indexed in Pubmed: 25616819.

22. Urena M, Webb JG, Tamburino C, et al. Permanent pacemaker implantation after transcatheter aortic valve implantation: impact on late clinical outcomes and left ventricular function. Circulation. 2014; 129(11): 1233-1243, doi: 10.1161/CIRCULATIONAHA.113.005479, indexed in Pubmed: 24370552.

23. Engborg J, Riechel-Sarup C, Gerke O, et al. Effect of permanent pacemaker on mortality after transcatheter aortic valve replacement. Scand Cardiovasc J. 2017; 51(1): 40-46, doi: 10.1080/14017431.2016.1236982, indexed in Pubmed: 27624406.

24. Barth S, Reents W, Zacher M, et al. Multicentre propensity-matched comparison of transcatheter aortic valve implantation using the ACURATE TA/neo self-expanding versus the SAPIEN 3 balloonexpandable prosthesis. EuroIntervention. 2019; 15(10): 884-891, doi: 10.4244/EIJ-D-18-01120, indexed in Pubmed: 31270034. 